\title{
Retirement homes: Social participation and quality of life
}

\author{
Elham Amiri ${ }^{1}$, Farzad Faraji Khiavi ${ }^{2}$, Hossine Dargahi ${ }^{3}$, Esmat Dastjerd ${ }^{4}$
}

${ }^{1}$ MSc in Rehabilitation Administration, School of Rehabilitation, Ahvaz Jundishapur University of Medical Sciences, Ahvaz, Iran

${ }^{2} \mathrm{PhD}$, Associate Professor, Social Determinants of Health Research Center, School of Health, Ahvaz Jundishapur University of Medical Sciences, Ahvaz, Iran

${ }^{3}$ Professor, PhD in Health Care Management, Health Information Management Research Center, Tehran University Of Medical Sciences, Tehran, Iran

${ }^{4}$ MSc in Rehabilitation Administration, School of Rehabilitation, Ahvaz Jundishapur University of Medical Sciences, Ahvaz, Iran

\section{Type of article: Original}

\begin{abstract}
Introduction: Social participation is considered as a means of improving one's quality of life, thus the study aimed at assessing the association between the quality of life and social participation in the elderly.

Methods: This cross-sectional study was conducted in 2016. The study population was selected from among the residents of a retirement home (an elderly residential home) in one of the Northwestern provinces of Iran, and the required data was collected via three questionnaires related to the demographic data, the specific quality of life for the elderly (LEIPAD), and the extent of social participation. Data was analyzed using mean, standard deviation, Spearman correlation coefficient, Mann-Whitney, Chi-square and Kruskal-Wallis test in SPSS software.

Results: The social participation level of the population under study was estimated as being appropriate (mean score: $3.81 \pm 0.32$ ); whereas, the respondents' quality of life was estimated as being relatively inappropriate (mean score: $2.78 \pm 0.41$ ). The "art, sport and leisure activities" subscale showed a significant relationship with the subscales related to the total quality of life and those of "Physical Performance" ( $r=0.128, p=0.46)$, "depression and anxiety"( $r=0.114, p=0.051)$, "sexual performance" $(r=0.213, p=0.21)$, and "life satisfaction" $(r=0.272, p=0.11)$; furthermore, there was a significant relationship between total social participation and "life satisfaction" and the subscales related to "depression and anxiety" $(\mathrm{r}=0.263, \mathrm{p}=0.12)$.
\end{abstract}

Conclusions: It seems that activities that involve the art, sport and leisure subscale of social participation can result in quality of life improvement for the elderly.

Keywords: Quality of life, Social participation, Elderly, Retirement home

\section{Introduction}

The population of elderly people is steadily increasing (1). According to the World Health Organization (WHO) the proportion of elderly people to that of the world population will rise from $6.4 \%$ in 2005 to reach $25.6 \%$ in 2050 (2). According to the 2012 National census, the elderly account for more than $8.26 \%$ of the Iranian population (3). The State Welfare Organization of Iran defines elderly persons as over 60 years old and declares, they need more care and rehabilitation due to age increasing and physiological changes (4). Increasing the elderly's social participation is a criterion recommendation by the World Health Organization to respond to concerns about the elderly (5). Social participation is defined as spending time for social interaction and mingling with others (6). Social participation, according to the International Classification of Functioning, Disability and Health (ICF), is further defined as a person involved in life situations (7); in addition, social participation is associated with the health and independence

\section{Corresponding author:}

Professor Dr. Hossine Dargahi, Health Information Management Research Center, Tehran University Of Medical Sciences, Tehran, Iran. Tel: +98.9123010027, Email: hdargahi@sina.tums.ac.ir

Received: May 07, 2016, Accepted: February 26, 2017, Published: April 2017

iThenticate screening: February 22, 2017, English editing: March 13, 2017, Quality control: April 02, 2017

(c) 2017 The Authors. This is an open access article under the terms of the Creative Commons Attribution-NonCommercialNoDerivs License, which permits use and distribution in any medium, provided the original work is properly cited, the use is non-commercial and no modifications or adaptations are made. 
in elderly people (8). Social participation among the elderly relates to functional skills, welfare, life expectancy and better quality of life (9). It is of note that participation in social activities may lead to provision of some informal social support networks for the elderly (10). If elderly people participated more in social activities, they would estimate their health level higher than others (11). One of the goals of the social rehabilitation plan for the elderly in the Islamic Republic of Iran is the active participation of the elderly in the managing of some roles and functions of the society that they live in (12). Increasing the elderly's social participation is a WHO recommended criterion to respond to concerns about the elderly (5); social participation is often used as an important measure for evaluating the quality of life (13). Enjoyment from life, understanding one's goals, and deriving happiness from daily life is sometimes believed to be out of reach for the elderly (14). Identifying the relationship between the quality of life and social participation involving the elderly can help in formulating some useful procedures regarding the improvement of the quality of life for the elderly. Elderly people amounted to $7.2 \%$ of the population in Ahvaz, based on a 2010 census. Yet, their quality of life was estimated inappropriate (15). Therefore, this study aimed at assessing the association between the quality of life and social participation in the elderly in Ahvaz, Iran.

\section{Material and Methods}

\subsection{Study Design}

This cross-sectional study was conducted in 2016. The study population included the residents of a retirement home in one of the cities in the Northwestern provinces Iran.

\subsection{Inclusion and exclusion criteria}

A list of all the elderly residents in this retirement home was prepared, and the inclusion and exclusion criteria were identified. Inclusion criteria were: staying in the center, an ability to communicate, and being aged 65 years or older. Exclusion criteria were: being more than 84 years old, and any psychological and/or physical disability. Based on these criteria, 35 elderly people filled the inventories. According to regulations of the State Welfare Organization of Iran, separation by gender is mandatory for founding a residential home for the elderly. In the city where the study and subsequent data was obtained, there is no residential home for elderly women.

\subsection{Data gathering tools}

The data collection tools used for the study consisted of three questionnaires. First, the demographic information questionnaire including age, sex etc. Second, the LEIPAD quality of life questionnaire, that was designed based on the Likert Scale, in which each question has four options from zero to three. This questionnaire has 31 questions for assessing the quality of life of the elderly in 7 subscales: physical performance, self-care, depression and anxiety, mental performance, social performance, sexual performance, life satisfaction (16). Validity was confirmed in Iran and Cronbach's Alpha of the questionnaire reported to be $0.83 \%$. (17). Mean score between 12 estimated as inappropriate, 2-3 as relatively appropriate and 3-4 as appropriate. Third, the Alavi and Mastaiz social participation questionnaire that was designed based on the Chapin Scale was used (18). This questionnaire included two kinds of questions; 19 Likert Scale items and 4 yes/no questions. These include four political activity, religious activities and charities, civil activity and finally art, sport and leisure activities subscales. The subjects recorded 76 points as the highest and 0 points as the lowest. The Cronbach's Alpha coefficient was stated as being 86\%. The mean score between 1-2 estimated as inappropriate, 2-3 as relatively inappropriate, 3-4 as relatively appropriate and 4-5 as appropriate.

\subsection{Statistical analysis}

The descriptive statistical analysis included the mean, standard deviation, and relative frequency. As for the inferential statistics, the Mann-Whitney, Chi-square and Kruskal-Wallis tests in SPSS software were used.

\section{Results}

The retirement home selected for the study was a male-only residential complex, so all respondents are of a single gender. Fifty-seven percent of the respondents were in the 65 to 74 years old age group ( $73.5 \pm 4.5$ years). Forty eight percent of them were illiterate, and the rest of them did not finish high school. Sixty percent of the respondents were widowers and $94 \%$ of the elderly lived in the retirement home, and others were provided day care there. The subscale mean scores for political activities, religious activities and charity, civil activities, art, sport and leisure activities, and social participation were $3.41 \pm 0.71,3.62 \pm 0.51,4.47 \pm 0.28,3.76 \pm 0.39$ and $3.81 \pm 32$ respectively. Based on the scores, social participation was estimated as being relatively appropriate. Furthermore, the score in the subscale civil activities was estimated as being appropriate, and other social participation subscales were estimated as being relatively appropriate also. The subscales' mean scores were: physical performance, self-care, depression \& 
anxiety, mental performance, social performance, sexual performance, and life satisfaction were $2.82 \pm 0.57$, $2.67 \pm 0.6,2.4 \pm 0.8,2.74 \pm 051,2.83 \pm 0.57,3.09 \pm 0.3$, and $2.94 \pm 0.35$ respectively. The mean score for the total quality of life was 2.78 \pm 0.41 . Among the seven subscales of LEIPAD quality of life questionnaire, the 'Sexual performance' subscale was estimated as being appropriate, and other subscales were estimated as relatively inappropriate. The total quality of life for the study population estimated as relatively appropriate. The Spearman correlation coefficient between the quality of life and social participation in the respondents is shown in Table 1. Although no significant association was observed between the total social participation and the total quality of life, there is a significant association between "art, sports and leisure activities", "physical performance", "depression and anxiety", "sexual performance", "life satisfaction" subscales and total quality of life. There was a significant association between the total social participation and that of "life satisfaction". There is also a significant association between the total social participation and "depression and anxiety". Table 1 provides information that the "religious activities and charity" subscale showed a significant medium association with quality of life $(\mathrm{p}=0.016)$. This social participation subscale demonstrated a large significant association with "life satisfaction", medium significant association with "depression and anxiety" and association with "social performance" subscales. The Kruskal-Wallis Test indicated a significant difference between various education levels in "physical activities" ( $\mathrm{p}=0.008)$, "selfcare" ( $p=0.006)$, "social activities" ( $p=0.015)$, "sexual activities" ( $p=0.011)$, "life satisfaction" ( $p=0.004)$, and the total quality of life $(\mathrm{P}=0.006)$. People with different marital statuses showed significant differences in the "life satisfaction" ( $\mathrm{p}=0.020)$ and "physical activities" $(\mathrm{p}=0.014)$ subscales. A significant difference was found in "sexual activities" between the different age groups, using the Mann-Whitney test. It showed 60 to 74 -year group with $3.24+0.26$ mean and standard deviation was significantly higher than 75 to 85 -year group with $2.98+0.31(\mathrm{p}=0.015)$.

Table 1. Spearman correlation between quality of life and social participation among respondents

\begin{tabular}{|c|c|c|c|c|c|c|}
\hline \multirow[t]{2}{*}{ Quality of life } & \multirow{2}{*}{$\begin{array}{l}\text { Statistical } \\
\text { Indicators }\end{array}$} & \multicolumn{5}{|c|}{ Subscales of Social Participation } \\
\hline & & $\begin{array}{l}\text { Political } \\
\text { Activities }\end{array}$ & $\begin{array}{l}\text { Religious } \\
\text { Activities and } \\
\text { Charity }\end{array}$ & $\begin{array}{l}\text { Civil } \\
\text { Activities }\end{array}$ & $\begin{array}{l}\text { Art, Sport } \\
\text { and Leisure } \\
\text { Activities }\end{array}$ & Total \\
\hline \multirow{2}{*}{$\begin{array}{l}\text { Physical } \\
\text { performance }\end{array}$} & Spearman corr. & 0.29 & 0.476 & 0.096 & 0.128 & 0.2 \\
\hline & $p$-value & 0.091 & 0.004 & 0.583 & 0.464 & 0.249 \\
\hline \multirow{2}{*}{ Self-care } & Spearman corr. & 0.118 & -0.011 & -0.05 & -0.302 & 0.298 \\
\hline & p-value & 0.498 & 0.951 & 0.776 & 0.078 & 0.151 \\
\hline \multirow{2}{*}{$\begin{array}{l}\text { Depression \& } \\
\text { Anxiety }\end{array}$} & Spearman corr. & 0.344 & 0.494 & 0.121 & 0.114 & 0.193 \\
\hline & $\mathrm{p}$-value & 0.043 & 0.003 & 0.489 & 0.515 & 0.268 \\
\hline \multirow{2}{*}{$\begin{array}{l}\text { Mental } \\
\text { performance }\end{array}$} & Spearman corr. & 0.302 & -0.017 & -0.034 & 0.049 & 0.316 \\
\hline & $\mathrm{p}$-value & 0.078 & 0.924 & 0.848 & 0.779 & 0.064 \\
\hline \multirow{2}{*}{$\begin{array}{l}\text { Social } \\
\text { performance }\end{array}$} & Spearman corr. & 0.183 & 0.241 & -0.141 & 0.162 & 0.281 \\
\hline & $p$-value & 0.293 & 0.162 & 0.421 & 0.352 & 0.102 \\
\hline \multirow{2}{*}{$\begin{array}{l}\text { Sexual } \\
\text { performance }\end{array}$} & Spearman corr. & 0.3 & 0.474 & 0.153 & 0.213 & 0.241 \\
\hline & p-value & 0.080 & 0.004 & 0.379 & 0.219 & 0.163 \\
\hline \multirow[t]{2}{*}{ Life satisfaction } & Spearman corr. & 0.345 & 0.512 & -0.071 & 0.272 & 0.263 \\
\hline & $p$-value & 0.042 & 0.002 & 0.684 & 0.114 & 0.127 \\
\hline \multirow[t]{2}{*}{ Total } & Spearman corr. & 0.294 & 0.403 & 0.03 & 0.058 & 0.246 \\
\hline & p-value & 0.086 & 0.016 & 0.865 & 0.741 & 0.155 \\
\hline
\end{tabular}

\section{Discussion}

In the current study, total social participation was estimated as being relatively appropriate; moreover, the participation in the "Civil Activities" subscale was estimated as being appropriate, and other social participation subscales were also estimated as appropriate. The results obtained in the study though, differed from those obtained in a similar research carried out by van der Slot (19). It is believed that this difference was probably due to the difference in the studied populations and data gathering tools. In this study, no association was observed between the total social participation and the total quality of life. The findings were in contrast to those of Levasseur et al. (20), Kave Firoz and Mohammadi (21), and Alizade et al. (22). In these studies, the study location and age range of the population were different. In addition, in this study, there were significant relationships found between the "art, sports and leisure activities" subscale and total quality of life as well as some of its subscales including "physical performance", "depression and anxiety", "sexual performance", and "life satisfaction". There was a significant relationship between the total social participation and "life satisfaction". Furthermore, there was a significant 
relationship between the total social participation and "depression and anxiety" subscales. Thus, it was proposed that by designing and implementing some programs in different fields of arts and sports, and other leisure activities for the elderly, some improvements can be made in the quality of life for residents in retirement homes. Dahalan and Ibrahim (2) showed that after 6 months of intervention in the social participation of the elderly, a significant change was seen in the physical, psychological, and social subscales of the quality of life. According to Levasseur et al. (23), the elderly's' quality of life and social participation were significantly related to their physical activity level. In the current study, the participant's total quality of life was estimated as being relatively inappropriate. This was similar to the results obtained by previous research $(12,24,25)$, but it was different from the results obtained by other researchers $(14,26,27)$. This study was conducted in a small town, but other studies have been conducted in the capital or major cities; this may lead to observed differences. The mean overall quality of life in the study carried out by Valadares et al. (29) was relatively appropriate. In the study done by Teston and Marcon (30), using the World Health Organization Quality of Life Questionnaire, the elderly were reported as having a good quality of life. The quality of life in a Brazilian study was estimated as being appropriate (31). In this study, different age groups had significant association in the "sexual activities" subscale of quality of life. That was similar to the research done by other researchers $(21,22,24)$. Arslantas et al. showed that with the increasing of age, the social and environmental dimensions of the quality of life is reduced (32). In the present study, different age groups showed no significant relationships in terms of quality of life, but the elder population had a lower quality of life. Other researches also indicate that with aging, the quality of life decreases. In this study, different groups, in terms of education level, showed a significant relationship in terms of "physical activities", "self-care", "social activities", "sexual activities", "life satisfaction", and total quality of life, which parallels a study conducted by other researchers $(5,14,27)$. This study was limited by a lack of institutions for the elderly in the studied province and the limited number of elderly with inclusion criteria. However, all members of the study population with inclusion criteria were convinced to participate in this study.

\section{Conclusions}

It is believed that some sort of interventions need to be planned in order to develop social partnership and enhance the quality of life of the elderly. It seems that art, sport and leisure activities can result in improvements in the quality of life. Therefore, for the improvement and advancement of the quality of life among the elderly, a combination of mentioned activities should be considered.

\section{Acknowledgments:}

This research was funded by the Health Information Management Research Center (HIMRC-TUMS) and approved by the Ethics Committee of Tehran University of Medical Sciences. Authors appreciate all the elderly who participated in this study.

\section{Conflict of Interest:}

There is no conflict of interest to be declared.

\section{Authors' contributions:}

All authors contributed to this project and article equally. All authors read and approved the final manuscript.

\section{References:}

1) Haywood KL, Garratt AM, Fitzpatrick R. Quality of life in older people: A structured review of generic self-assessed health instruments. Qual Life Res. 2005; 14(7): 1651-68. doi: 10.1007 /s11136-005-1743-0. PMID: 16119178.

2) Aghanouri A, Salehi H, Jafarian K. Quality of life of elderly people covered by health centers in urban areas of the Central Province in 2012. Salmand. 2012; 6(22): 20-9.

3) Yazdani A, Fekrazad H, Sajadi H, Salehi M. Relationship between social participation and general health among the elderly. Journal of Kermanshah University of Medical Sciences. 2015; 18(10): 599-606.

4) Iran Behzisti Organization. Aging Population in Iran. 2015. Available From: www.behzisti.ir/

5) Lima MG, Barros MBdA, César CLG, Goldbaum M, Carandina L, Ciconelli RM. Health related quality of life among the elderly: A population-based study using SF-36 survey. Cad Saude Publica. 2009; 25(10): 2159-67. doi: 10.1590/S0102-311X2009001000007.

6) Maier H, Klumb PL. Social participation and survival at older ages: Is the effect driven by activity content or context? Eur J Ageing. 2005; 2(1): 31-9. doi: 10.1007/s10433-005-0018-5. 
7) Mikula P, Nagyova I, Krokavcova M, Vitkova M, Rosenberger J, Szilasiova J, et al. Social participation and health-related quality of life in people with multiple sclerosis. Disabil Health J. 2015; 8(1): 29-34. doi: 10.1016/j.dhjo.2014.07.002. PMID: 25130596.

8) Ichida Y, Hirai H, Kondo K, Kawachi I, Takeda T, Endo H. Does social participation improve self-rated health in the older population? A quasi-experimental intervention study. Soc Sci Med. 2013; 94: 83-90. doi: 10.1016/j.socscimed.2013.05.006. PMID: 23931949.

9) Dahan-Oliel N, Gelinas I, Mazer B. Social participation in the elderly: What does the literature tell us? Crit Rev Phys Rehabil Med. 2008; 20(2): 159-76.

10) Chiao C, Weng LJ, Botticello AL. Social participation reduces depressive symptoms among older adults: An 18-year longitudinal analysis in Taiwan. BMC Public Health. 2011; 11(1): 292. doi: 10.1186/14712458-11-292.

11) Nummela O, Sulander T, Rahkonen O, Karistoc A, Uutelaa A. Social participation, trust and self-rated health: A study among ageing people in urban, semi-urban and rural settings. Health Place. 2008; 14(2): 243-53. doi: 10.1016/j.healthplace.2007.06.006.

12) Moradi S, Fekrazad H, Mousavi M. Examine the relationship between social participation and quality of life of elderly members of Tehran in 2012. salmand. 2013; 7(27): 41-6.

13) Bukov A, Maas I, Lampert T. Social participation in very old age: cross-sectional and longitudinal findings from BASE. Berlin Aging Study. J Gerontol B Psychol Sci Soc Sci. 2002; 57(6): P510-7. doi: 10.1093/geronb/57.6.P510. PMID: 12426433.

14) Naing MM, Nanthamongkolchai S, Munsawaengsub C. Quality of life of the elderly people in einme township irrawaddy division, Myanmar. Asia J Public Health. 2010; 1(2): 4-10.

15) Borzoo S, Arsto A, Ghasmezade R, Zahednejad Sh, Habibi A, Latifi M. The effect of aerobic exercise on quality of life of the elderly living in nursing homes in Ahvaz. Salmand. 2010; 6(19): 47-51.

16) Mohaqeqi Kamal H, Sajadi H, Zare H, Beiglarian A. Elderly quality of life: A comparison between pensioners of social security organization and national retirement fund (Qom County, 2006). Journal of Health Administration. 2007; 10(27): 49-56.

17) Ghasmi H, Harirchi M, Mansori AA, Rah gozar M, Akbarin M. Compare the quality of life of elderly residents and families living in nursing homes in Isfahan. Social Welfare Quarterly. 2009; 10(39): 177-200.

18) Ellaway A, Macintyre S. Is social participation associated with cardiovascular disease risk factors? Soc Sci Med. 2007; 64(7): 1384-91. doi: 10.1016/j.socscimed.2006.11.022. PMID: 17196313.

19) Van der Slot WM, Nieuwenhuijsen C, Van den Berg-Emons RJ, Wensink-Boonstra AE, Stam HJ, Roebroeck ME. Participation and health-related quality of life in adults with spastic bilateral cerebral palsy and the role of self-efficacy. J Rehabil Med. 2010; 42(6): 528-35. doi: 10.2340/16501977-0555. PMID: 20549157.

20) Levasseur M, Desrosiers J, Noreau L. Is social participation associated with quality of life of older adults with physical disabilities? Disabil Rehabil. 2004; 26(20): 1206-13. doi: 10.1080/09638280412331270371. PMID: 15371021.

21) Kaveh firoz Z, Mirzaei M. Tehran's quality of life and participation in social activities with emphasis on gender. Iranian Journal of Sociolog. 2010; 4(8): 123-48.

22) Alizadeh S, Mohseni M, Khanjani N, Momenabadi V. Correlation between social participation of women and their quality of life in Kerman. Journal of Health Promotion Management. 2014; 3(2): 34-42.

23) Dahlan A, Ibrahim SAS. Effect of Lively Later Life Programme (3LP) on Quality of Life amongst Older People in Institutions. Procedia Soc Behav Sci. 2015; 202: 252-62. doi: 10.1016/j.sbspro.2015.08.229.

24) Levasseur M, Desrosiers J, St-Cyr Tribble D. Do quality of life, participation and environment of older adults differ according to level of activity? Health Qual Life Outcomes. 2008; 6: 30. doi: 10.1186/14777525-6-30. PMID: 18445262, PMCID: PMC2412860.

25) Nabavi SH, Shoja M, Mohammadi S, Rashedi V. Health-related quality of life in community-dwelling older adults of Bojnourd, 2014. Journal of North Khorasan University of Medical Sciences. 2014; 6(2): 433-9.

26) Dlova NC, Fabbrocini G, Lauro C, Spano M, Tosti A, Hift RH. Quality of life in South African Black women with alopecia: A pilot study. Int J Dermatol. 2016; 55(8): 875-81. doi: 10.1111/ijd.13042. PMID: 26547604.

27) Habibi A, Namadi vosoughi M, Habibi S, Mohammadi M. Quality of Life and Prevalence of Chronic Illnesses among Elderly People: A Cross-Sectional Survey. Ardabil University of Medical Sciences. 2012; 3(1): 58-66. 
28) Rezvani MR, Mansourian H, Ahmadadadi H, Ahmadadadi F, Parvayi here dasht Sh. An Assessment on Factors Affecting the Quality of Life of Elderly in Rural Regions (Case Study: Neishabour County). Rural Research. 2013; 4(2): 301-26.

29) Valadares AL, Carvalho ED, Costa-Paiva LH, Morais SS, Pinto-Neto AM. Association between different types of physical activities and quality of life in women aged 60 years or over. Rev Assoc Med Bras. 2011; 57(4): 450-5. doi:10.1590/S0104-42302011000400021. PMID: 21876929.

30) Ferraz Teston E, Silva Marcon S. Comparative study of quality of life of elderly living in condominiums versus community dwellers. Invest Educ Enferm. 2015; 33(1): 53-62. doi: 10.1590/S012053072015000100007. PMID: 26148156.

31) Rodrigues GH, Gebara OC, Gerbi CC, Pierri H, Wajngarten M. Depression as a Clinical Determinant of Dependence and Low Quality of Life in Elderly Patients with Cardiovascular Disease. Arq Bras Cardiol. 2015; 104(6): 443-9. doi: 10.5935/abc.20150034. PMID: 26131699 , PMCID: PMC4484676.

32) Arslantas D, Unnsal A, Metintas S, Koc F, Arslantas A. Life quality and daily life activities of elderly people in rural areas, Eskişehir (Turkey). Arch Gerontol Geriatr. 2009; 48(2): 127-31. doi: 10.1016/j.archger.2007.11.005. PMID: 18215432. 